\title{
Effect of an Increase in Heart Rate on the Pumping Function of the Heart Ventricles in Cold-Blooded Animals under Low Ambient Temperature Conditions
}

\author{
Natalya A. Kibler*, PhD; Vladimir P. Nuzhny, PhD, ScD; Dmitry N. Shmakov, PhD, ScD \\ Institute of Physiology, Komi Science Center, Ural Branch of the RAS \\ Syktyvkar, Komi Republic, Russia
}

\begin{abstract}
This study investigated the effect of heart rate (HR) on the pumping function of the heart ventricle $(\mathrm{HV})$ in rainbow trout Oncorhynchus mykiss acclimated to a temperature of $5-7^{\circ} \mathrm{C}$, and in adult frogs Rana temporaria at an ambient temperature of $10-12^{\circ} \mathrm{C}$. The dynamics of intracavitary ventricular pressure was recorded by transmural catheterization. HR was changed by atrial electrocardiostimulation. The increase in HR in rainbow trout resulted in a decrease in the maximal systolic ventricular pressure (MSVP), an increase of end-diastolic ventricular pressure (EDVP), and a reduction in the maximum rates of the rising and falling pressures. In the frog, MSVP and isovolumic parameters ( $\mathrm{dP} / \mathrm{dt}_{\max }$ and $\mathrm{dP} / \mathrm{d}_{\text {tmin }}$ ) also decreased as HR increased from 24 bpm to 42 $\mathrm{bpm}$. The preload of the frog's HV did not change significantly, compared to the sinoatrial rhythm (SR). The maximum increase in the frequency of atrial stimulation up to $60 \mathrm{bpm}$ in fish and up to $42 \mathrm{bpm}$ in frogs resulted in a significant decrease in the myocardial contractility and deterioration of the pumping function of HV under low ambient temperature conditions. (International Journal of Biomedicine. 2020;10(3):262-265.)
\end{abstract}

Key Words: pumping function $\bullet$ heart rate $\bullet$ heart ventricle $\bullet$ temperature $\bullet$ rainbow trout $\bullet$ frog

\section{Abbreviations}

EDVP, end-diastolic ventricular pressure; HR, heart rate; HV, heart ventricle; MSVP, maximal systolic ventricular pressure; SR, sinoatrial rhythm.

\section{Introduction}

Any stressful changes in the environment trigger a complex of physiological reactions, mainly associated with an increase in cardiac output, which is realized by increasing HR. ${ }^{(1)}$ In cold-blooded vertebrate amphibians, HR variability is considered as a factor that ensures the activity of the heart in extreme conditions that go beyond the usual conditions in the organism's habitat. ${ }^{(2)}$

In lower ectothermic (cold-blooded) vertebrates in natural conditions, slow sinoatrial heart rhythm ${ }^{(3,4)}$ and the

*Corresponding author: Natalya A. Kibler, PhD; Laboratory of Cardiac Physiology, Institute of Physiology, Komi Science Center, Ural Branch of the RAS, Syktyvkar, Komi Republic, Russia. E-mail address: natanadya@mail.ru degree of organization of the cardiac conduction system ${ }^{(5,6)}$ do not allow a significant increase in HR. In amphibians, however, an increase in habitat temperature to $20^{\circ} \mathrm{C}$ results in an increased HR, accompanied by improvement in the contractile function of the ventricle. (7) In fish, especially salmon, cardiac output increases during active movement. During this time, the stroke volume and, to a lesser degree $\mathrm{HR}$, is responsible for the rise of cardiac output during swimming. Increasing the temperature of the surrounding water environment from $3^{\circ} \mathrm{C}$ to $10^{\circ} \mathrm{C}$ is accompanied by a significant increase in HR; however, during these conditions, stroke volume and cardiac output vary in different fish species. ${ }^{\left({ }^{8}\right)}$ In a study conducted on strips of ventricular myocardium, ${ }^{(9)}$ the increased HR in rainbow trout (Oncorhynchus mykiss) in vitro at $4^{\circ} \mathrm{C}, 10^{\circ} \mathrm{C}$, and $18^{\circ} \mathrm{C}$, acclimated to $10^{\circ} \mathrm{C}$, revealed no changes in the myocardial contractile function. Currently, 
there are insufficient studies of the regularities of the influence of HR on the contractile function of the heart in amphibians and fish at low temperature conditions at which effective cardiac activity is maintained. ${ }^{(10)}$ It is important to conduct a model study of the contractile function of HV in cold-blooded animals (fish and amphibians)at different HRs in low ambient temperature conditions.

The study of the contractile properties of $\mathrm{HV}$ with a functionally homogeneous spongy myocardium in lower ectothermic vertebrates (fish and amphibians) under electrocardiostimulatory myocardial stress (an increased HR) will help to explain the mechanisms of the heart function.

The purpose of this work is to study the influence of $\mathrm{HR}$ increase on the contractile properties of $\mathrm{HV}$ in fish and amphibians, by modified atrial electrocardiostimulation in low temperature conditions.

\section{Materials and Methods}

\section{Animals and surgical procedure}

This investigation conforms with the Guide for the Care and Use of Laboratory Animals published by the US National Institutes of Health (NIH Publication No. 85-23, revised 1996). The Animal Care and Use Committee of Institute of Physiology of the Komi Science Center of the Russian Academy of Sciences approved the experimental protocol (approved number: 29).

Fish. The experiments were carried out on 14 rainbow trout (Oncorhynchus mykiss) of both sexes, weighing 1.1 \pm 0.2 $\mathrm{kg}$, adapted for several weeks to the natural water temperature of $5-7^{\circ} \mathrm{C}$ in pond-farm cages. Each fish was immobilized and fixed in a water-filled tray with its body positioned on the back. A rubber hose was inserted into the oral cavity, through which, to provide artificial respiration, river water at a temperature of $5-7^{\circ} \mathrm{C}$ was continuously passed through the gills under low pressure. The body temperature of the experimental animals during the study was maintained within $5-7^{\circ} \mathrm{C}$. A longitudinal incision was used to open the chest cavity and pericardium, exposing the heart and the myocardium of the ventricle.

Frog. Experiments were performed on 14 adults (2-3 years old) frogs (Rana temporaria) of both sexes, weighing $34 \mathrm{~g}-47 \mathrm{~g}$. All animals demonstrated normal sinus rhythm on an ECG. The frogs were anaesthetized by placing them for 3 minutes in a jar containing $40 \%$ ethanol. After that, the ventral thoracic wall was removed and the pericardium was cut open. During the experiment, the body temperature of each animal was in the range of $10-12^{\circ} \mathrm{C}$ and the heart was flushed with warm Ringer's solution $\left(10-12^{\circ} \mathrm{C}\right)$. In the laboratory, the animals' body temperature equilibrated rapidly with an ambient temperature that corresponded to the data of other researchers. At the end of the experiment, the animals were euthanized by an intravenous injection of an overdose of alcoholic solution.

\section{Hemodynamic recording}

In both fish and frogs, the hemodynamic variables were determined with the Prucka Mac Lab 2000 system (GE Medical System, GmbH). The pressure in the ventricle was measured with a catheter (internal diameter, $1 \mathrm{~mm}$ ) filled with the heparinized $0.9 \%$ saline inserted via the free wall into the ventricular cavity.
Invasive monitoring of the pressure was carried out using transducers, transforming blood pressure inside of the vessels as the transducer registered mechanical changes. Intraventricular pressure and ECG in standard bipolar limb leads were recorded synchronously. Hemodynamic parameters measured included: MSVP (mmHg), EDVP (mmHg), maximal value of the MSVP derivative $\left(\mathrm{dP} / \mathrm{dt}_{\text {max }}, \mathrm{mmHg} / \mathrm{s}\right)$, maximal rate of MSVP decline $\left(\mathrm{dP} / \mathrm{dt}_{\text {min }}, \mathrm{mmHg} / \mathrm{s}\right)$. The durations of QRS complex and QT interval were measured also.

\section{Pacing}

The HR in fish was changed by pacing with a CEECX-3 pacemaker. The atrium was stimulated, with the stimuli lasting $2 \mathrm{~ms}$ and amplitude $2-4 \mathrm{~V}$ in the range from sinus rhythm to the maximum HR, at which disorders occurred in heart activity. In our study, HR of $60 \mathrm{bpm}$ is the maximum frequency in trout under the given temperature conditions, above which rhythm disturbance occurred.

In frogs, HR was changed by pacing the right atrium from 0.4 to $0.7 \mathrm{~Hz}$ with step $0.1 \mathrm{~Hz}(24-42 \mathrm{bpm})$. The right atrium was stimulated with cathodic impulses (duration 3.5ms; twice-diastolic threshold). The amplitude of impulses was $3-5 \mathrm{~V}$. The duration of pacing period was $1 \mathrm{~min}$.

The results were statistically analyzed using BIOSTAT 4.03 program with use of Wilcoxon and Mann-Whitney criterion. Data are presented as mean \pm standard deviation $(\mathrm{M} \pm \mathrm{SD})$. A probability value of $P<0.05$ was considered statistically significant.

\section{Results}

Fish. The initial HR at SR ranged from $18 \mathrm{bpm}$ to 27 bpm at $\mathrm{t}=5-7^{\circ} \mathrm{C}$. The duration of the QRS complex in the ECG increased at $\mathrm{HR}$, increasing to $60 \mathrm{bpm}(148.3 \pm 21.4 \mathrm{~ms} ; P<0.05)$, relative to SR $(102.7 \pm 12.5 \mathrm{~ms})$. The QT interval shortened with the increase in HR up to $60 \mathrm{bpm}(506.6 \pm 93.0 \mathrm{~ms} ; P<0.05)$, relative to SR (1208.2 $\pm 249.4 \mathrm{~ms})$.

MSVP was significantly reduced $(P<0.02)$ at imposed rhythms from $30 \mathrm{bpm}$ to $60 \mathrm{bpm}$, relative to SR (Fig.1).

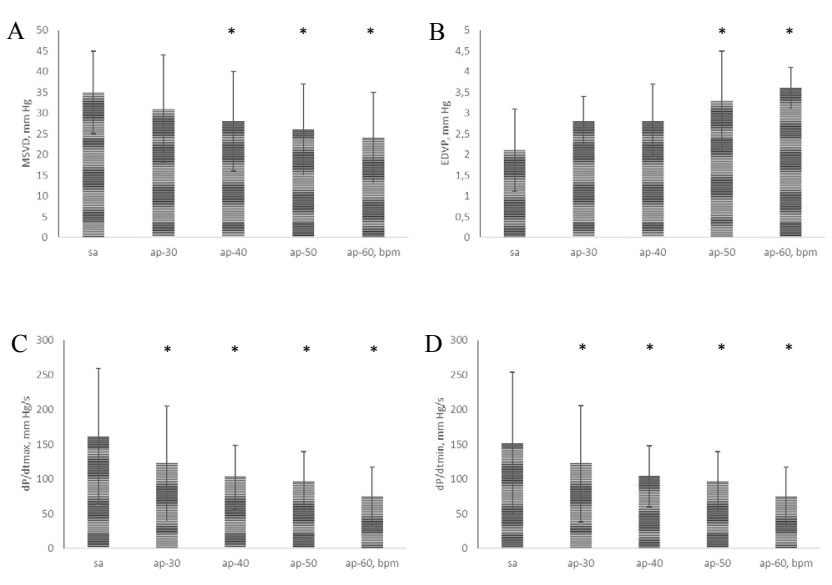

Fig 1. Hemodynamic parameters of the heart of rainbow trout with an increase in HR: A-MSVP; $B$ - EDVP; $C$ - the maximum rate of the ventricular pressure rise $\left(d P / d t_{\text {mat }}\right) ; D$ - the maximum rate of the pressure fall $(d P / d t$ sa - sinus rhythm; ap - atrium pacing rhythm. $30, \ldots, 60-H R$ in beats/min, respectively. ${ }^{*} P<0.05-$ in relation to the sinus-atrial rhythm. 
During this time, EDVP increased significantly with the increase in HR, compared to SR. Increased HR led to a synchronous change in the isovolumic indices $\left(\mathrm{dP} / \mathrm{dt}_{\text {max }}\right.$ and $\left.\mathrm{dP} / \mathrm{dt}_{\text {min }}\right)$. Starting with the frequency of $30 \mathrm{bpm}$ and up to a maximum of $60 \mathrm{bpm}$, these indicators were reduced $(P<0.02)$, relative to SR.

Frog. At $\mathrm{t}=10-12^{\circ} \mathrm{C}$, HR in frogs ranged from $23 \mathrm{bpm}$ to $29 \mathrm{bpm}$. The duration of the QRS complex did not significantly change with the increase in HR (from 27 to $44 \mathrm{bpm}$ ), compared to SR (76.2 $\pm 20.8 \mathrm{~ms})$, which distinguishes the change in this indicator obtained in fish. The duration of the QT interval decreased $(P<0.05)$ with the increase in HR, compared to SR. MSVP and isovolumic indices $\left(\mathrm{dP}^{\mathrm{d}} \mathrm{dt}_{\max }\right.$ and $\left.\mathrm{dP} / \mathrm{dt}_{\text {min }}\right)$ decreased $(P<0.05)$ with the increase in the imposed HR from $32 \mathrm{bpm}$ to $44 \mathrm{bpm}$. However, the preload of HV in frogs with the increased HR did not significantly change, compared to SR (Fig.2), in contrast to the resulting EDP in fish.

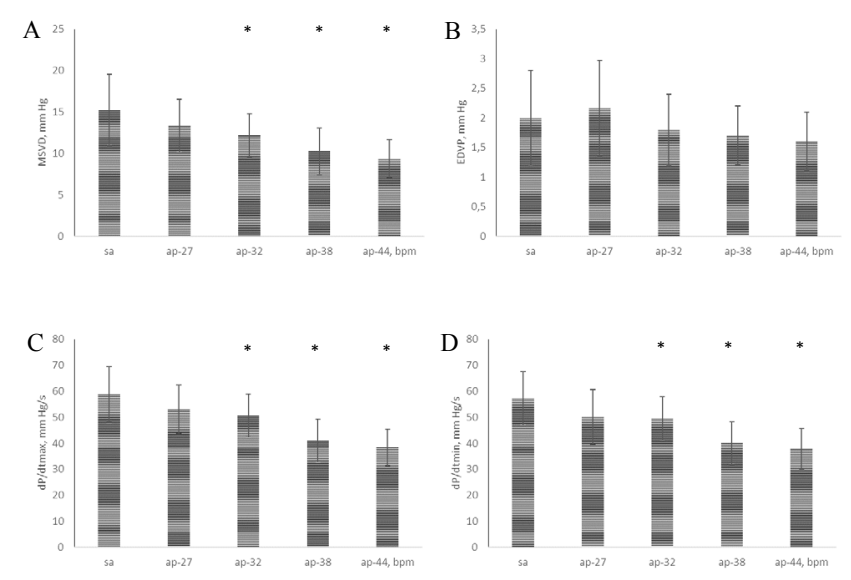

Fig. 2. Hemodynamic parameters of the heart of frog with an increase in HR: A-MSVP; $B$ - EDVP; $C$ - the maximum rate of the ventricular pressure rise $\left(d P / d t_{m q)}\right) ; D$ - the maximum rate of the pressure fall $\left(d P / d t_{\text {min }}\right.$ sa-sinus rhythm; ap - atrium pacing rhythm. $27, \ldots, 44$ - HR in bpm, respectively. ${ }^{*} P<0.05$ - in relation to the sinus rhythm.

\section{Discussion}

Fish. In relation to the initial rhythm in trout, MSVP, $\mathrm{dP} / \mathrm{dt}_{\max }$ and $\mathrm{dP} / \mathrm{dt}_{\min }$ decreased while EDVP increased with the increase of HR. In rainbow trout adapted to a temperature of $5-7^{\circ} \mathrm{C}$ at SR in the frequency range of $21.6 \pm 4.9 \mathrm{bpm}$, the pumping function of the heart was probably within the upper limit of the physiological norm and the further increase in HR caused its deterioration. Previously, research on myocardial strips by Coyne et al. showed that the pumping function of the HV muscle in trout depends on the concentration of intracellular and extracellular calcium, and that changes in HR do not significantly affect the contractile function.

The ion channels of the fish heart, being plastic objects, actively react to the electrical parameters of the heart, depending on the ambient conditions and the way of life of fish. The density and kinetics of the sodium current (INa) are essential for generating the action potentials in fish myocardium. For example, at low temperatures, in burbot and rainbow trout the high INa density supports a relatively high HR. ${ }^{(1)}$ Because the main role in activating contraction in the fish myocardium is given to the flow of extracellular $\mathrm{Ca}^{2+}$ through the sarcolemma, the electromechanical synchronization and direction of myocardial contraction are limited not only by the size, but also by the duration and direction of the action potential. ${ }^{(12)}$

It has been established ${ }^{(13)}$ that an increase in HR by more than 2 times (in our study, increasing HR in fish up to $60 \mathrm{bpm}$ ) reduces the functional heterogeneity of the myocardium, which is manifested in almost simultaneous depolarization of the layers in the ventral and dorsal parts of the ventricle, which indicates how intensely those parts are involved in the contractile process. The functional homogeneity of the depolarization process of the myocardium is probably related to the almost simultaneous opening of $\mathrm{Na}^{+}-$and $\mathrm{Ca}^{2+}$ dependent channels, which increases the contribution of the calcium component of the depolarizing current to enhancing the operation of the $\mathrm{Na} \backslash \mathrm{Ca}$ pump under $\mathrm{Ca}^{2+}$ cardiomyocyte overload. ${ }^{(14)}$ In our experiment, in the electrocardiogram in fish during atrial stimulation with the frequency exceeding the physiological HR, the changes in the QT interval that were revealed may be a result of the formation of dynamic functional heterogeneity of the myocardium. As a result, HR exceeds the ability of cardiomyocytes to provide intracellular $\mathrm{Ca}^{2+}$ homeostasis with the formation of the conduction block, which is manifested in the ECG by the broadening of the QRS complex. ${ }^{(14)}$

At the maximum imposed HR of $60 \mathrm{bpm}$, we found a short period in which hemodynamic parameters were stabilized, the so-called limit of reducing the contractile properties of HV. The increase in the ventricular preload in trout with the increase in HR is due to the increased contribution of $\alpha$-adrenoreceptors, which compensates for the reduction in the time it takes for the ventricle to fill. It is possible that, under the conditions of our experiment, with increased preload and reduced contractility of HV, the mechanism of homeostatic physiological functions of the myocardium is activated, at which the maximum HR of $60 \mathrm{bpm}$ is the maximum functionally effective frequency. Above that frequency, there develop structural disorders in $\mathrm{HV}$ and fatal rhythm disturbance. Thus, an increase in HR at the artificial atrial rhythm at a constant water temperature (5$7^{\circ} \mathrm{C}$ ) does not improve the contractile properties of $\mathrm{HV}$ in fish. In contrast, the results obtained earlier ${ }^{(13)}$ suggest that with the increase of HR the mechanical load on the ventricular base area is distributed and the electrical and mechanical properties of the ventricular myocardium are desynchronized.

Frog. Previously, we showed that in amphibians one of the mechanisms for maintaining the functional activity of the heart in conditions of high ambient temperature with an increase in HR is an increase in electrical heterogeneity on the ventral surface of the ventricle in the area of the arterial cone. ${ }^{(2)}$ The discovered electrical heterogeneity of the myocardium indicates that the myocardial tissue of the amphibian heart is able to change its functional properties depending on external conditions. (7) Regionally determined changes in the electrophysiological properties of the myocardium are based on the changes in metabolism throughout the body. ${ }^{(15)}$ Electrical stimulation of the atrium at the increase in HR in amphibians does not cause an increase in EDVP, unlike in fish. Rather, it reduces the systolic 
blood pressure and isovolumic parameters of HV. It is known that the modulating effect on the strength and HR is realized through changing the action potential in order to discharge cardiomyocytes when performing excessive load. ${ }^{(16)}$ During an increase of HR beyond the physiological norm for this species, this mechanism apparently stops working, which leads to the phenomenon of calcium overload of cardiomyocytes. The natural variability of $\mathrm{HR}$ as a factor of increasing the contractile function is realized through the increase in the electrical heterogeneity of the myocardium, while high HR reduces the electrical heterogeneity of the myocardium, and is the cause of changes in the contractile properties of the heart. Thus, we have shown that the increase in HR above the typical indicators for amphibians at an ambient temperature of $18-20^{\circ} \mathrm{C}$ is accompanied by a decrease in the contractile function of the myocardium. ${ }^{(2)}$

Thus, the increased HR in lower cold-blooded animals under low habitat temperature leads to a significant decrease in the myocardial contractility, as well as deterioration of the pumping function of $\mathrm{HV}$, and it cannot be considered as an adaptive factor that ensures the activity of the heart in extreme conditions that go beyond the usual habitat of the animal.

\section{Acknowledgements}

This study was supported by RFBR (Project No AAAA-A17-117012310154-6).

\section{Competing Interests} interests.

The authors declare that they have no competing

\section{References}

1. Farrell AP, Eliason E, Sandblom E, Clark TD. Fish cardiorespiratory physiology in an era of climate change. Canad J Zool. 2009;87(10):835-851.

2. Kibler NA, Nuzhny VP, Achmetzhynova SV, Shmakov DN. Effects of Heart Rate on the Pump Function and Electrophysiological Characteristics of the Heart in the Frog Rana temporaria. International Journal of Biomedicine. 2017;7(1):46-50. doi: 10.21103/Article7(1)OA5.

3. Davies F, Francis ET. The conducting system of the vertebrate heart. Biol Rev Camb Phylos Soc. 1946;21(4):173188. doi:10.1111/j.1469-185x.1946.tb00323.x

4. Moorman AF, Christoffels VM. Cardiac chamber formation: development, genes and evolution. Physiol Rev. 2003;83(4):1223-1267. doi:10.1152/physrev.00006.2003

5. Sedmera D, Reckova M, deAlmeida A, Sedmerova M,
Biermann M, Volejnik J, et al. Functional and morphological evidence for a ventricular conduction system in zebrafish and Xenopus hearts [published correction appears in Am J Physiol Heart Circ Physiol. 2003 Aug;285(2):H919]. Am J Physiol Heart Circ Physiol. 2003;284(4):H1152-H1160. doi:10.1152/ ajpheart.00870.2002

6. Jensen J, Wang T, Christoffels VM, Moorman AFM. Evolution and development of the building plan of the vertebrate heart. Biochimica et Biophysica Acta. 2013; 1833(4):783-94. doi: 10.1016/j.bbamcr.2012.10.004.

7. Kibler NA, Nuzhny VP, Prosheva VI. Electrical and Contractile Properties of the Heart Ventricle in Response to Ambient Temperature Changes in Frog Rana temporaria. International Journal of Biomedicine. 2017;7(3):180-184. doi: 10.21103/Article7(3)OA4.

8. Sandblom E, Farrell AP, Altimiras J, Axelsson M, Claireaux G. Cardiac preload and venous return in swimming sea bass (Dicentrarchus labrax L.). J Exp Biol. 2005;208(Pt 10):1927-1935. doi:10.1242/jeb.01606

9. Coyne MD, Kim KC, Cameron JS, Gwathmey JK. Effects of temperature and calcium availabilityon ventricular myocardium from rainbow trout. Am J Physiol Regulatory Integrative Comp Physiol. 2000;278(6):R1535-R1544. doi:10.1152/ajpregu.2000.278.6.R1535

10. Kopp R, Schwerte T, Pelster B. Cardiac performance in the Zebrafish Breakdance Mutant. J Exp Biol. 2005; 208:21232134. doi: 10.1242/jeb.01620.

11. Haverinen J, Vornanen M. Temperature acclimation modifies $\mathrm{Na}+$ current in fish cardiac myocytes. J Exp Biol. 2004;207(Pt 16):2823-2833. doi:10.1242/jeb.01103

12. Vornanen M, Shiels HA, Farrell AP. Plasticity of excitation-contraction coupling in fish cardiac myocytes. Comp Biochem Physiol A Mol Integr Physiol. 2002;132(4):827-846. doi:10.1016/s1095-6433(02)00051-X

13. Kibler NA, Nuzhny VP, Kharin SN, Shmakov DN. Does Atrial Electrical Stimulation to the Sequence of Depolarization of the Ventricles of Rainbow Trout Oncorhynchus mykiss? J Evol Biochem Physiol. 2020;56(1):42-47. doi: 10.31857/ S0044452920010052.

14. Glukhov AV, Egorov YuV, Rozenshtrauh LV. [Electrophysiological mechanisms of stability of the heart rhythm of hibernating mammals during hypothermia]. Usp Fiziol Nauk. 2014;45(1):3-26. [Article in Russian].

15. Seebacher F, Franklin CE. Physiology of invasion: cane toads are constrained by thermal effects on physiological mechanisms that support locomotor performance. J Exp Biol. 2011;214(Pt 9):1437-1444. doi:10.1242/jeb.053124

16. Shemarova IV, Kuznetsov SV, Demina IN, Nesterov VP. [T-channels and $\mathrm{Na}+, \mathrm{Ca} 2+$-exchangers as components of the $\mathrm{Ca} 2+$-system of the myocardial activity regulation of the frog Rana temporaria]. J Evol Biochem Physiol. 2009;45(3):319328. [Article in Russian]. 